\title{
МОНИТОРИНГ УДОВЛЕТВОРЕННОСТИ ОБРАЗОВАНИЕМ ВЫПУСКНИКОВ ВУЗОВ КАК ИНСТРУМЕНТ УПРАВЛЕНИЯ УЧЕБНЫМ ПРОЦЕССОМ
}

\section{MONITORING OF SATISFACTION WITH EDUCATION OF UNIVERSITY GRADUATES AS A TOOL FOR MANAGING THE EDUCATIONAL PROCESS}

\section{N. Anufrieva \\ E. Grigorieva \\ A. Kamyanets}

Summary: The article discusses the possibilities of monitoring studies of the satisfaction of university graduates as an additional resource for improving the organization of the educational process. The results obtained are compared with the results of monitoring carried out in other universities. The analysis of the general state of the organization of the educational process is carried out when studying the data obtained through monitoring; reveals the main methodological approaches to this research procedure, which may be of interest to a wide range of specialists and researchers who practice monitoring research and organize teaching and educational work at the university.

Keywords: education, monitoring, quality of education, university graduates, satisfaction with education.

\section{Введение}

$\mathrm{M}$ ониторинг как исследовательская процедура получает все более широкое распространение в управленческой деятельности, включая организацию образовательного процесса в высших учебных заведениях. В образовательной сфере мониторинговые исследования позволяют принимать своевременные управленческие решения по совершенствованию и развитию всех сторон деятельности учебного заведения. Востребованность таких исследований возрастает в связи с изменением всей ситуации подготовки кадров в высших учебных заведениях, где образовательные услуги все больше встраиваются в систему рыночных отношений, предполагающих максимальный учет разнообразных запросов учащихся.

Эти запросы могут рассматриваться как удовлетворенность получаемым образованием, которая зависит как от качества работы самого вуза, так и от многих проблем современного социума $[5,24]$. Особое значение в этом исследовании приобретает проведение систематических мониторингов отношения к полученному
Ануфриева Наталья Ивановна Д.п.н., профессор, ФГБОУВО «Российский государственный сочиальный университет» nata415485@mail.ru

Григорьева Елена Ивановна

Д.культурологии, профессор, ФГБОУ ВО «Российский государственный социальный университет»

Каменец Александр Владленович

Д.культурологии, професссор, ФГБОУ ВО «Российский государственный социальный университет» kamenez.a@rambler.ru

Аннотация: В статье рассматриваются возможности мониторинговых исследований удовлетворенности выпускников вуза в качестве дополнительного ресурса совершенствования организации образовательного процесса. Проводится сопоставление полученных результатов с результатами мониторингов, проведенных в других вузах. Осуществляется анализ общего состояния организации учебного процесса при изучении данных, полученных с помощью мониторинга; раскрываются основные методические подходы к данной исследовательской процедуре, которые могут представлять интерес для широкого круга специалистов и исследователей, практикующих мониторинговые исследования и организующих учебно-воспитательную работу в вузе.

Ключевые слова: образование, мониторинг, качество образования, выпускники вузов, удовлетворенность образованием.

образованию выпускников вузов, способных оценить весь процесс полученного образования на всех этапах его организации. В научной литературе, посвященной анализу результатов таких исследований, выявлена система показателей удовлетворенности образованием окончившими высшие учебные заведения, которая может рассматриваться как система соответствующих ориентиров для дальнейшего совершенствования высшего профессионального образования в нашей стране [13].

Выявленные показатели представляют собой отражение как объективных, так и субъективных факторов образовательного процесса, которые являются взаимосвязанными. Наиболее оптимальным путем выявления этой взаимосвязи является движение от изучения субъективных факторов, где главная роль принадлежит удовлетворенности получаемым образованием самих студентов, к объективным факторам (реальным условиям обучения, месту и роли данного вуза в образовательном пространстве, реальному общественному спросу на данные образовательные услуги и т.д.). Именно такая логика определила направленность проведенного мониторинга в Российском государственном социальном 
университете в 2020 году научным коллективом факультета искусств.

\section{Методика}

Методика мониторингового исследования строилась как выявление качества образовательной деятельности вуза на основе как количественных показателей анкетного опроса, так и с помощью интервьюирования [20, $21,22]$. Соответствующие количественные показатели удовлетворенности выпускников РГСУ полученным образованием способствовали получению относительно завершенных представлений о реальной роли данного вуза на рынке рабочих мест, а также оценке полученного образования самими учащимися. Причем именно первый из этих результатов рассматривался в качестве основного, а второй как производный, что соответствует рекомендациям исследователей, изучающих образовательный процесс в вузе [4].

Для получения более полной картины удовлетворенности выпускников полученным образованием проводился сопоставительный анализ их предварительных ожиданий от вузовского образования и реальным отношением к вузу уже после его окончания. Тем самым устанавливались соответствующие встречаемые расхождения между ожиданиями и конечным отношением выпускников к полученному образованию в качестве важного ориентира дальнейшего совершенствования образовательного процесса. Причины такого расхождения выяснялись как в самой организации учебного процесса и его качества, так и в учебно-познавательных запросах самих выпускников. Это позволило при интерпретации полученных исследовательских результатов избежать двух крайностей - выводов о необходимости безоговорочно следовать в организации вузовского образования запросам студентов или необходимости формирования уже на стадии приема в вуз набора желательного учебного контингента только в соответствии с имеющейся учебно-образовательной стратегией.

Изучение результатов мониторинговых исследований выпускников других вузов позволило выделить в качестве приоритетных для проводимого мониторинга такие аспекты образовательного процесса как уровень и содержание образования; ориентированность всего учебного процесса на соответствующие специальности и профессии; возможности компенсаций платы за обучение, начиная от необходимости наличия бюджетных мест, кончая различные бонусы в платном обучении в зависимости от учебной успеваемости; включение вуза в трудоустройство выпускников; умение вуза формировать собственную положительную репутацию в существующем образовательном пространстве [14].

Сформированность в большинстве вузов технологий дистанционного образования позволяет выдвигать на первый план новые критерии его качества. Последнее теперь определяется не только содержательностью и компетентностью профессорско-преподавательского состава, но и умением соотносить тот или иной учебнопознавательный материал с запросами студентов, ориентируясь на наглядность, аттрактивность, эмоциональность и другие запросы студентов, на увлекательность самого учебного процесса, что в известной мере может компенсировать дефицит непосредственного межличностного взаимодействия педагогов и учащихся в имеющейся виртуальной образовательной среде [9, 18].

В этой связи необходима более широкая трактовка таких традиционных требований к качеству образования как профессионализм педагогов; коммуникативная культура профессорско-преподавательского состава; интерес самих педагогов к преподаваемым учебным дисциплинам; связь с практикой; современное педагогическое мышление [16].

Все эти требования к образовательному процессу изучались в плоскости удовлетворенности выпускников полученным образованием как некоторого индикатора уровня организации всей учебно-воспитательной работы вуза.

\section{Результаты}

В процессе исследования были получены результаты, позволившие оценить обе ступени образовательного процесса - бакалавриат и магистратуру, осуществив их сопоставительный анализ в контексте удовлетворенности полученным образованием. Так, окончившие бакалавриат, оказались настроены гораздо более критично по отношению к организации учебного процесса фактически по всем его компонентам. Магистры же в целом оценили намного выше образовательный процесс практически во всех основных аспектах.

Наиболее высоко были оценены как бакалаврами, так и магистрами профессионализм педагогов, формирование у студентов стремления работать в соответствии с профессиональной подготовкой после окончания вуза. Зато крайне низко были оценены такие компоненты учебной работы как организация производственной практики и управленческая деятельность, обеспечивающая успешность образовательного процесса.

Эти результаты свидетельствуют об отсутствии должной взаимосвязи между деятельностью педагогов и административно-управленческого звена в работе вуза, что существенно снижает эффективность всей учебновоспитательной работы. Складывается парадоксальная ситуация - те, кто руководит профессорско-преподавательским составом, и кто несет на себе основную орга- 
низационно-управленческую нагрузку в вузе получают больше всего критических замечаний со стороны выпускников.

Сопоставляя основные результаты проведенного мониторинга с аналогичными исследованиями в других вузах, можно сделать вывод о необходимости в дальнейшем более углубленного изучения именно организационно-управленческой деятельности в этих учебных заведениях, в задачи которой должно входить обеспечение качества образования через соответствующие организационные технологии. Это: всесторонняя работа с абитуриентами по формированию у них устойчивой мотивации к учебной деятельности как к процессу, а не только как к средству получения диплома о высшем образовании; поддерживание высокого уровня мотивации к обучению в процессе всего образовательного цикла благодаря уделения внимания проблемам и запросам каждого студента; своевременное выявление наиболее способных и добросовестных студентов и оказание им помощи в последующем трудоустройстве; интенсивная работа административно-управленческого персонала вуза на рынке труда будущих молодых специалистов $[6,7]$.

Результаты проведенного мониторинга показывают, что он имеет смысл, если является составной частью более широкого процесса изучения всей организации учебного процесса, что подтверждается результатами других исследований [4].

Неудовлетворенность многих выпускников уровнем организации образовательной деятельности в вузе связано с проявлением случаев «голого администрирования» со стороны некоторых организаторов учебного процесса при дефиците «обратной связи» в учебно-воспитательной работе. Очевидно, что акцент в управлении образованием в вузах должен быть смещен в сторону взаимоуважительного диалога и партнерства между организаторами учебного процесса и студентами. Соответственно проведенный мониторинг показал наличие больших потенциальных возможностей для дальнейшего решения этой проблемы.

В этой связи принцип интерактивности во взаимоотношениях студентов и всех сотрудников вузов, как отмечают некоторые исследователи, призван создать еще больше условий для самостоятельной работы студентов и их самореализации [3].

Неудовлетворенность многих выпускников состоянием учебно-производственной практики есть следствие недостаточной эффективной организационной работы в этом направлении. Очевидно, что силами только профессорско-преподавательского состава эту задачу решить невозможно. Необходимо дальнейшее выстраи- вание организационной стратегии всех подразделений вуза в установлении более тесных и разнообразных контактов с базами практики, создания условий для успешного проведения последней.

Проведенный мониторинг показал, что еще пока мало исследованной темой остается научно-исследовательская деятельность студентов, которая также является существенным фактором формирования у выпускников удовлетворенности полученным образованием $[1,12]$.

Некоторыми выпускниками высказывалась неудовлетворенность сложившейся психологической атмосферой в вузе. Между тем, на этот фактор удовлетворенности вузовским образованием обращают внимание и другие исследователи [15].

В то же время отмечается, что создание благожелательной и творческой атмосферы во многом зависит и от самих студентов. Не случайно исследователями выделяются как активные, так и пассивные студенты в отношении к формируемому микроклимату в студенческих коллективах [17].

Еще одна конкретизация требования повышения управленческой культуры в вузах заключается в дальнейшем совершенствовании форм контроля за учебным процессом при отсутствии их излишней мелочности и чрезмерной детализации [23].

Основным же мотивирующим началом в учебно-познавательной деятельности студентов должно стать формирование у них установки на получение образования как необходимого условия дальнейшей успешной профессиональной карьеры [11]. Именно этому должна быть подчинена организация учебного процесса в вузах. О реалистичности формирования такой установки свидетельствуют результаты и других исследователей [8, $10]$.

Именно на таких выпускников и ориентированы преимущественно современные работодатели [2, 19].

\section{Обсужмение}

Нельзя не отметить, что в процессе проведения мониторингов необходимо рассматривать раздельно удовлетворенность получаемым образованием студентов с отличной и хорошей успеваемостью и студентов, которые не отличаются высокой успеваемостью. Это необходимо и для всей организации учебного процесса. Если для хорошо успевающих студентов необходимо создавать дополнительные условия для их личностного и профессионального роста, то для неуспевающих студентов важно устранять основные причины их неудовлетво- 
рительного отношения к учебным заданиям. При этом соответствующие управленческие решения не должны носить исключительно репрессивный характер, но быть направлены на устранение причин неуспеваемости и в случае необходимости оказания помощи таким студентам в соответствии с компетенциями вуза.

Нельзя также не отметить необходимости специальной работы над технологиями и исследовательскими инструментами мониторинга с учетом специфики учебновоспитательного процесса в вузе и концепции развития учебного заведения.

Необходимо также осуществлять специальную работу по созданию методики интерпретации получаемых ответов респондентов на языке решения соответствующих учебно-воспитательных задач. Так, при проведении любого опроса любой исследователь должен иметь в виду, что высказываемое опрашиваемыми мнение через письменный или устный опрос есть мнение, а не реальное поведение респондентов. Поэтому результаты опроса должны быть обязательно сопоставлены с реальным учебным процессом, его организацией. Это: успеваемость студентов, изучение реальной организации учебного процесса, стиль управления вузом, качество учебно-методической литературы, уровень преподавания, организация студенческого досуга, участие студентов в общественных мероприятиях, наличие возможностей установления неформальных межличностных контактов как в самой студенческой среде, так и между студентами и преподавателями, перспективность получаемых в вузе профессий и специальностей, взаимодействие с реальными и потенциальными работодателями, взаимоотношения внутри преподавательских коллективов, наличие в вузе корпоративной культуры, реальная загруженность педагогов и административно-управленческого персонала, дифференцированный подход к обучению с учетом социальных, психологических и культурных особенностей студентов.

В современной образовательной ситуации возрастает также роль самих педагогов как субъектов организации учебного процесса. В этой связи представляется перспективным систематическое проведение мониторинговых исследований самим профессорско-преподавательским составом, направленных на повышение эффективности собственной педагогической деятельности. В такой мониторинг можно включить следующие вопросы для изучения: индивидуально-психологические особенности студентов и выпускников, имеющие отношение к учебному процессу; причины неуспеваемости того или иного студента; культурный кругозор и индивидуальные познавательные интересы студентов; творческие способности и досуговые ориентации; взаимоотношения с одногруппниками; базовые жизненные и ценностные ориентации.

Вовлеченность педагогов в мониторинговые исследования предполагает изменение всего стиля их взаимоотношений со студентами. Он должен состоять в осуществлении постоянного диалога с учебным контингентом в направлении выяснения возникающих затруднений и проблем в усвоении материала, в умелом установлении неформальных межличностных взаимоотношений между педагогами и студентами с целью более глубокого взаимопонимания на основе сближения ценностно-мировоззренческих позиций и отношения к учебному процессу.

\section{Зак^ючение}

Проведенный мониторинг удовлетворенности выпускников полученным образованием показал перспективность данной исследовательской процедуры для совершенствования всей организации образовательной деятельности вуза. Выяснилось, что сами обучающиеся могут рассматриваться как авторитетные эксперты при оценке эффективности учебного процесса. Данные письменного опроса дополнялись интервьюированием выпускников, проявивших глубокую заинтересованность в получении конструктивных ответов на поставленные вопросы.

Результаты проведенного мониторинга позволяют сделать вывод о наличии реальных предпосылок для дальнейшего развития университета не столько за счет дополнительных материальных и кадровых ресурсов, сколько за счет оптимизации организации всего учебного процесса благодаря продуманной системе взаимосвязей различных специалистов без ущемления прав и чрезмерных производственных перегрузок всех работников вуза.

Выстраиваемая таким образом система должна включать в себя следующие взаимосвязанные функциональные блоки: материально-техническая база вуза, профессорско-преподавательский состав, административно-управленческий персонал, студенчество, финансово-правовое обеспечение. Если один из этих блоков функционирует без связи с другими, возникают перекосы в организации работы вуза, существенно отражающиеся отрицательным образом на ее эффективности.

\section{Б^агодарности}

*Публикация в рамках научно-исследовательской работы по теме «Мониторинг удовлетворенности выпускников качеством подготовки по образовательным программам», согласно приказу РГСУ №530 от 30.04.2020 «О реализации внутренних научно-исследовательских работ за счет РГСУ» 


\section{ЛИТЕРАТУРА}

1. Алешковский И.А., Гаспаришвили А.Г., Крухмалова О.В. Опыт социологического анализа системы образования региона России на примере Кемеровской области. - М.: МАКС Пресс, 2019. - 411 с.

2. Артамонова М.В. Реформа высшей школы и Болонский процесс в России. - М. Экономика, 2008. - 278 с.

3. Боброва Т.А. Современная система высшего образования Российской Федерации: основные проблемы и пути их решения//Молодой ученый. Киберленинка, 2018 - №45 (231). - С. 127 - 130.

4. Болотов В.А., Ефремова Н.Ф. Система оценки качества образования. Учебное пособие. - М: Логос, 2007. - 192 с.

5. Бордовский Г.А. Модели и методы внутреннего и внешнего оценивания качества образования в вузах. - Спб.: Кн.дом, 2008. - 338 с.

6. Васильева Е.Ю., Солодов С.В., Кочетов Д.А., Кочетов А.И. Мониторинг удовлетворенности работодателей качеством выпускников вузов: монография М.: Изд.Дом МИСиС, 2013. -259 с.

7. Вашурина Е.В. Рекомендации по диверсификации источников финансирования и обеспечению необходимой инфраструктурой федеральных университетов, включая рекомендации по реализации комплекса решений, направленных на стимулирование развития учреждений ВП0 и их конкуренции за бюджетные места / Е.В. Вашурина, Н.В. Дрантусова, Я.Ш. Евдокимова: Материалы конференции «Формирование сети федеральных университетов: ключевые подходы и принципы, Москва: 2008. - с.121-196

8. Воловская Н.М., Плюснина Л.К. Внутренний социологический мониторинг качества образовательной деятельности вуза//Теория и практика общественного развития, Киберленинка,2015.

9. Галеева Р.Б. Маркетинговые исследования в образовании: монография. - М.: Дашков и К, 2007. - 159 с.

10. Голышев И.Г. Управление качеством образования в вузе: поиск модели. - Чебоксары: Новое время, 2006. - 150 с.

11. Дидковская Я.В. Успешность профессиональной карьеры молодежи в трансформирующемся обществе// Социологические науки №96. Октябрь, 2015. C.64-68.

12. Елисеева Е.Н. Оценка удовлетворенности потребителей образовательных услуг на факультете управления//Вестник Челябинского государственного университета,2013, №3 (294). Управление. Вып.8 - С.107 - 110.

13. Ермакова Ж.А., Никулина Ю.Н. Качество образования с позиции потребителей образовательных услуг вуза//Креативная экономика. Т.11, №7, июль 2017. - Оренбург: Изд-во Креативная экономика. Оренбургский гос. ун-т. - С.726- 735.

14. Киселева М.В. Вовлечение обучающихся вуза в оценку и повышение качества образования//Вестник КГУ им. Н.А. Некрасова, 2016. Т.22. - С.142 - 147.

15. Миляева Л.Г. Анализ успешности трудоустройства выпускников вузов в условиях компетентностного подхода//Управление человеческими ресурсами. Сб.науч.трудов. Вып.2- Новосибирск: НГУЭУ, 2016. - С.176- 186.

16. Мищенко Л.В. Интегративная психология пологендерного развития человека: Учебное пособие. - М.: КНОРУС, Пятигорск. - Пятигорский гос.лингвистический ун-т, 2016. - $301 \mathrm{c}$.

17. Погребицкая М.В. Система потребительского мониторинга вуза//Качество образования: менеджмент, достижения, проблемы: Материалы У1 Международной научно-методической конференции. - Новосибирск: Изд-во НГТУ, 2005. - С.291-297.

18. Помельникова Е.А. Субъектная позиция будущего специалиста к успешной профессиональной деятельности как основа профессионального самоопределения//0бразование, инновации, исследования как ресурс развития сообщества: материалы Международной научно-практической конференции. - Чебоксары: ИД «Среда», 2017. - С.83.

19. Русанова А.А. Удовлетворенность как показатель качества образования в современном вузе (из опыта конкретного социологического исследования). Новосибирск, НГТУ, 2005. - 380 с.

20. Степанов С.А. Всеобщий менеджмент качества: учебное пособие /С.А. Степанов. - СПб.: ЛЭТИ, 2001. - 164с.

21. Управление качеством подготовки специалистов в высшей школе: теория и практика: коллект. Монография. - Волгоград: Перемена, 2008. - 260 с.

22. Фаткулин А.А. Современное образование: управление, качество, инновации: Учебное пособие. - Владивосток: Изд-во ДВГТУ, 2007. - 128 с.

23. Филиппова И.В. Мониторинг удовлетворенности потребителей качеством подготовки специалистов в Мордовском государственном университете// Вестник Мордовского ун-та. - 2007. №1. Серия «Экономические науки» - С.21 - 23.

24. Шлыков Г.П. Система менеджмента качества университета. - М.: НТК «Трек», 2008. - 300 с.

(c) Ануфриева Наталья Ивановна (nata415485@mail.ru), Григорьева Елена Ивановна, Каменец Александр Владленович (kamenez.a@rambler.ru). Журнал «Современная наука: актуальные проблемы теории и практики» 